University of Nebraska - Lincoln

DigitalCommons@University of Nebraska - Lincoln

Finance Department Faculty Publications

Finance Department

$10-2007$

\title{
An Empirical Examination of Jump Risk in U.S. Equity and Bond Markets
}

Lee M. Durham

University of Nebraska-Lincoln, Idunham2@unl.edu

Geoffrey C. Friesen

University of Nebraska-Lincoln, gfriesen2@unl.edu

Follow this and additional works at: https://digitalcommons.unl.edu/financefacpub

Part of the Finance and Financial Management Commons

Durham, Lee M. and Friesen, Geoffrey C., "An Empirical Examination of Jump Risk in U.S. Equity and Bond Markets" (2007). Finance Department Faculty Publications. 3.

https://digitalcommons.unl.edu/financefacpub/3

This Article is brought to you for free and open access by the Finance Department at DigitalCommons@University of Nebraska - Lincoln. It has been accepted for inclusion in Finance Department Faculty Publications by an authorized administrator of DigitalCommons@University of Nebraska - Lincoln. 


\title{
An EMPIRICAL EXAMINATION Of JUMp Risk IN U.S. EQUITY AND BOND MARKETS
}

\author{
Lee M. Dunham* and Geoffrey C. Friesen ${ }^{\dagger}$
}

\begin{abstract}
Actuaries manage risk, and asset price volatility is the most fundamental parameter in models of risk management. This study utilizes recent advances in econometric theory to decompose total asset price volatility into a smooth, continuous component and a discrete (jump) component. We analyze a data set that consists of high-frequency tick-by-tick data for all stocks in the S\&P 100 Index, as well as similar futures contract data on three U.S. equity indexes and three U.S. Treasury securities during the period 1999-2005. We find that discrete jumps contribute between 15\% and $25 \%$ of total asset risk for all equity index futures, and between $45 \%$ and $75 \%$ of total risk for Treasury bond futures. Jumps occur roughly once every five trading days for equity index futures, and slightly more frequently for Treasury bond futures. For the S\&P 100 component stocks, on days when a jump occurs, the absolute jump is between $80 \%$ and $90 \%$ of the total absolute return for that day. We also demonstrate that, in the cross section of individual stocks, the average jump beta is significantly lower than the average continuous beta. Cross-correlations within the bond and stock markets are significantly higher on days when jumps occur, but stockbond correlations are relatively constant regardless of whether or not a jump occurs. We conclude with a discussion of the implications of our findings for risk management.
\end{abstract}

\section{INTRODUCTION}

Actuaries manage risk, and asset price volatility is the most fundamental element of risk management. Therefore, actuaries must understand asset price volatility. Beginning with Merton (1976), financial economists have modeled price volatility as a combination of a smooth and continuous process, along with a much less persistent jump process (e.g., the jump-diffusion model). A thorough understanding of both the continuous and jump components of volatility is required to manage risk effectively.

Until recently it has been difficult for actuaries and financial economists to separate jumps from the underlying diffusion process when estimating parameters in a jump-diffusion model, in part because the actual jump is not readily observable from the time-series data of the underlying asset returns. Most jump parameter estimates are based on numerical simulations, since direct estimates are difficult to obtain in all but a few special cases (Aït-Sahalia 2004). Tauchen and Zhou (2006) note that "the main message from the empirical literature seems to be that jumps are very important in asset pricing, but the estimation of jump parameters and the pricing of jump risk are not easy to implement." This poses a serious practical challenge to actuaries and other risk managers.

This study examines the distributional properties of jumps for a large sample of U.S. stocks, stock index futures contracts, and U.S. Treasury Bond futures contracts by utilizing econometric techniques recently developed by Anderson, Bollerslev, and Diebold (2007), Barndorff-Nielsen and Shephard (2004), and Tauchen and Zhou (2006). These studies have demonstrated that by using high-frequency

\footnotetext{
* Lee M. Dunham, CFA, is a PhD Candidate, University of Nebraska-Lincoln, Lincoln, NE 68588-0490, Idunham2@unl.edu.

$\dagger$ Geoffrey C. Friesen, ASA, is Assistant Professor of Finance at the University of Nebraska-Lincoln, Lincoln, NE 68588-0490, gfriesen2@unl.edu.
} 
trade-by-trade data, one can effectively separate the continuous and jump components of the underlying price process. They demonstrate that one can accurately estimate the total volatility and the volatility of the underlying continuous-time process with measures they call the "Realized Volatility" (RV) and "Bi-power Variation" (BV) measures, respectively. The difference between these two measures provides an unbiased estimate of the jump component of prices.

Several recent papers have applied these techniques to limited sets of high-frequency data. Anderson, Bollerslev, and Diebold (2007) apply their methodology to a single exchange rate time series, a single futures contract, and a single U.S. Treasury bond. Tauchen and Zhou (2006) examine the S\&P 500 Index, a U.S. Treasury bond futures contract, Microsoft stock, and the Brazilian reais. Thus, the first contribution of the current study is to apply these newly developed estimation techniques to a broad cross section of data, examining for the first time the variations in jump risk across a large number of assets. Specifically, we decompose total volatility into its continuous and discrete components for every stock in the S\&P 100 Index, for three U.S. equity index futures, and for the 30-, 10-, and 2-year U.S. Treasury futures.

In addition, we further decompose each of the volatility components into their systematic and nonsystematic constituents. The importance of systematic risk has been well understood since the advent of the Capital Asset Pricing Model (Sharpe 1964). By regressing excess returns for an individual asset on the excess returns of the market, one can estimate in principle the asset's systematic risk, measured by the regression beta. Historically, however, the estimation of systematic risk has been done exclusively at the level of total risk. To our knowledge, ours is the first empirical study to decompose jump risk into its systematic and nonsystematic parts.

The difference between continuous betas and jump betas has important implications for risk management: with a total beta, one knows only the average level of systematic risk. However, given an asset's continuous and jump betas, one can explicitly calculate the asset's systematic risk conditional on whether or not the market experiences a jump. This is important for risk managers: if an asset behaves differently during a severe market downturn than it does at other times, this information offers the potential to significantly improve on ealculations such as Value at Risk (VAR). Moreover, if assets are combined in a well-diversified portfolio, then the asset's systematic jump risk is more relevant than the asset's total jump risk. This highlights the importance of decomposing total jump risk into its systematic and nonsystematic components.

Specifically, we find that jump betas are significantly lower than continuous betas, which indicates that stocks co-move with the market much less on days when the market experiences a jump. The average stock in our sample has a total beta of 0.68 . The average continuous beta is 0.80 , but the average jump beta is only 0.29 . We also demonstrate that jumps account for $80-90 \%$ of total daily return on days when jumps occur, so the jump beta is the most relevant measure of co-movement with the market on days when the market experiences a jump.

We also study the correlation between different asset classes. Although asset cross-correlations have been previously examined, the added contribution of our study is that we can calculate not only unconditional correlations between stock and bond index futures, but also the correlations between the continuous and jump components. We find that the correlation between one stock index and another stock index is significantly higher on jump days than nonjump days, and bond-bond correlations also differ significantly between jump and nonjump days. However, stock-bond correlations are relatively constant regardless of whether a jump has occurred. In addition, continuous returns are more strongly correlated than jumps, both within and across asset classes. This suggests that asset allocation models that utilize stock-bond cross-correlations may be more robust to the presence of asset price jumps than models that rely on estimates of cross-correlations within stock and bond markets.

The rest of the article is organized as follows. Section 2 discusses the empirical methodology used to identify statistically significant jumps. Section 3 describes the data, Section 4 presents our empirical results, and Section 5 concludes. 


\section{Jump Detection Methodology}

This section describes the empirical methodology utilized for this study, which is developed in Anderson, Bollerslev, and Diebold (2007), Barndorff-Nielsen and Shephard (2004), and Tauchen and Zhou (2006). Let $p(t)$ denote the time-t logarithmic price of the asset. The continuous-time jump diffusion process traditionally used in asset pricing is usually expressed as a stochastic differential equation:

$$
d p(t)=\mu(t) d t+\sigma(t) d W(t)+\kappa(t) d q(t), \quad 0 \leq t \leq T,
$$

where $\mu(t)$ is a continuous and locally bounded variation process, $\sigma(t)$ is a stochastic volatility process, and $W(t)$ denotes standard Brownian motion. The counting process $d q(t)=1$ corresponds to a jump at time $t$ and $d q(t)=0$ otherwise, and $\kappa(t)$ and is a measure of the size of the jump, conditional on a jump occurring. The quadratic variation for the cumulative return process, $r(t) \equiv p(t)-p(0)$, is given by

$$
[r, r]_{t}=\int_{s=0}^{t} \sigma^{2}(s) d s+\sum_{0<s \leq t} \kappa^{2}(s) .
$$

In the absence of jumps, the second term on the right-hand side disappears, and the quadratic variation simply equals the integrated (continuous) volatility.

Let the discretely sampled $\Delta$-period returns be denoted by $r_{t, \Delta} \equiv p(t)-p(t-\Delta)$, and define the daily realized volatility by the summation corresponding to $1 / \Delta$ high-frequency intradaily squared returns, ${ }^{1}$

$$
R V_{t+1}(\Delta) \equiv \sum_{j=1}^{1 / \Delta} r_{t+j \Delta, \Delta}^{2}
$$

For notational simplicity and without loss of generality, $1 / \Delta$ is assumed to be an integer. Then, as shown by Andersen and Bollerslev (1998), by the theory of quadratic variation the realized volatility converges uniformly in probability to the increment in the quadratic variation process defined above, as the sampling frequency of the underlying returns increases; that is,

$$
R V_{t+1}(\Delta) \rightarrow \int_{s=0}^{t} \sigma^{2}(s) d s+\sum_{0<s \leq t} \kappa^{2}(s) .
$$

In the absence of jumps, the realized volatility consistently estimates the integrated volatility. Define the standardized realized bi-power variation measure,

$$
B V_{t+1}(\Delta) \equiv \mu_{1}^{-2} \sum_{j=2}^{1 / \Delta}\left|r_{t+j \Delta, \Delta}\right|\left|r_{t+(j-1) \Delta, \Delta}\right|,
$$

where $\mu_{1}^{-2}=\sqrt{2 / \pi}$. Then, as the sampling frequency increases,

$$
B V_{t+1}(\Delta) \rightarrow \int_{s=0}^{t} \sigma^{2}(s) d s
$$

Thus, the contribution to the quadratic variation process due to discontinuities (i.e., jumps) can be consistently estimated by

$$
R V_{t+1}(\Delta)-B V_{t+1}(\Delta) \rightarrow \sum_{0<s \leq t} \kappa^{2}(s) .
$$

This is the fundamental insight upon which the estimation of the jump processes in this research is based.

\footnotetext{
${ }^{1}$ In our empirical work we divide each trading day into five-minute intervals. For example, in the case of individual stocks, each trading day consists of 78 five-minute intervals. Thus, $\Delta=1 / 78$.
} 
Following Tauchen and Zhou (2006) we define the ratio statistic

$$
R J_{t}=\frac{R V_{t}-B V_{t}}{R V_{t}}
$$

which, when scaled by its asymptotic variance, $R J_{t}$ converges to a standard normal distribution in the absence of jumps. That is, if no jumps occur on day $t$, then

$$
Z J_{t}=\frac{R J_{t}}{\sqrt{\left\{\left(\frac{\pi}{2}\right)^{2}+\pi-5\right\} \frac{1}{m} \max \left(1, \frac{T P_{t}}{B V_{t}^{2}}\right)}} \rightarrow N(0,1),
$$

where $m=1 / \Delta$ and $T P_{t}$ is the tri-power quarticity robust to jumps as shown by Barndorff-Nielsen and Shephard (2004). The tri-power quarticity measure is approximated by

$$
T P_{t} \equiv m \mu_{4 / 3}^{-3} \frac{m}{m-2} \sum_{j=3}^{m}\left|r_{t, j-2}\right|^{4 / 3}\left|r_{t, j-1}\right|^{4 / 3}\left|r_{t, j}\right|^{4 / 3} \rightarrow \int_{t-1}^{t} \sigma_{s}^{4} d s,
$$

where $\mu_{k}=2^{k / 2} \Gamma((k+1) / 2) / \Gamma(1 / 2)$ for $k>0$.

Based on the simulation and Monte Carlo experiments of Tauchen and Zhou (2006), we choose a 0.999 level of significance for the identification of jumps. Under this assumption, jumps occur on all days for which $\left|Z J_{t}\right|>3.0$, though for robustness we also report results for threshold values of 2.0 and 4.0. We assume that at most one jump occurs per day, and calculate the actual jump magnitude as $J_{t}=\operatorname{sign}\left(r_{t}\right) \times \sqrt{\left(R V_{t}-B V_{t}\right) \times I_{t}}$, where $I_{t}$ is an indicator variable equal to one if a jump occurs, and zero otherwise. ${ }^{2}$

\section{Data}

We collect intraday high-frequency bid-and-ask quote data both for individual stocks and for stock and bond index futures contracts. The individual stock data cover the component stocks of the S\&P 100 Index as of July 1, 2006, and are taken from the NYSE's Trade and Quote (TAQ) database for the sixyear sample period January 1, 1999-December 31, 2005. We use only quotes from NYSE, AMEX, and NASDAQ exchanges. ${ }^{3}$ Two component firms, United Postal Service and Goldman Sachs, went public during the sample period, and therefore we have quote data from the IPO date through the end of the sample period. Twelve firms in the S\&P 100 Index changed tickers during our sample period, mostly resulting from merger and acquisition activity, which required us to obtain TAQ data for both tickers. In our regression analysis, we use the S\&P 500 Index futures contract as a proxy for the market portfolio.

We mitigate the degree of bid-ask bounce in our sample data by using the bid-ask midpoint for each transaction. Our initial analysis of the TAQ quotes data revealed a number of erroneous quotes in the database, and we therefore apply a number of filters to eliminate these bad observations. First, we

\footnotetext{
${ }^{2}$ At a fundamental level, our methodology simply seeks to identify jump returns that cannot be adequately described by the continuous diffusion-only model. Thus, one can think of jumps as significant "outliers" under the diffusion-only specification. Although other techniques have been used to identify jumps or outliers in financial data, our methodology differs from many of these in both the nature of the jumps as well as the high frequency of the financial data used. In particular, we use the term jump to describe a large, almost instantaneous return deviation from an underlying continuous process. In other contexts the term jump has been used to describe a switch, or "jump," from one regime to another, where each regime has its own specification for the data-generating process. For example, Hardy (2001) considers a tworegime model for monthly equity returns in which the return mean and variance differ between the regimes. Cao and Tsay (1992) apply a Threshold Autoregression Model with two regime specifications also to monthly stock data. While one can think of "jumping" from one regime to another, this differs from the type of jump we are describing.

${ }^{3}$ The only S\&P 100 Index component stock not included in the study is CBS Corporation, which replaced Viacom on the S\&P 100 Index on January 1, 2006, a date just outside our sample period.
} 
require that the offer/bid ratio be less than 1.10 for the quote to be included. ${ }^{4}$ Second, we utilize a sandwich filter that eliminates quotations that are $10 \%$ or further in absolute value from surrounding quotes on both sides. The latter filter eliminates the following type of erroneous quote sequence: a first quote that is immediately followed by a significantly higher (or lower) second quote that is subsequently followed by a third quote that is consistent with the first quote in the sequence. ${ }^{5}$ Visual inspection of several firms revealed a number of these spurious quotes "sandwiched" between two otherwise consistent quotes, and our filter eliminates the erroneous quote. Without this filter, our estimation model might incorrectly identify a significant jump when prices jump to the erroneous quote and then jump back to the correct price.

Daily tick-by-tick quote data for the stock and bond futures contracts are obtained from the Institute for Financial Markets. ${ }^{6}$ The stock index futures include the Dow 30, Russell 2000, and S\&P 500, while the bond data are obtained for 2-, 10-, and 30-Year U.S. Treasury futures.

For each investment instrument, we include only quotes during regular trading hours and segment each trading day into five-minute intervals; we then calculate interval price returns using the midpoint of the bid-offer spread. We calculate the price return for an interval at time $t$ as $\log \left(\right.$ midpoint $_{t} /$ midpoint $_{t-1}$ ). For the first trading interval of each day, we utilize the opening daily midpoint quote and calculate the first interval return using the midpoint quote calculated at the end of the first interval. ${ }^{7}$ Since trading hours vary across instruments, the number of five-minute intervals calculated each day for each instrument is different. ${ }^{8}$ Some trading days in our sample period do not contain the full number of intervals as a result of holiday-shortened trading, temporary stoppages in trading, or other miscellaneous reasons. After creating the five-minute intervals for each of the component stocks, we eliminate any daily interval with a five-minute return greater than $50 \%$ in an attempt to control for stock splits.

\section{Empirical Results}

\subsection{Empirical Properties of the Data}

Table 1 presents cross-sectional summary statistics for realized volatility and bi-power variation for all 99 individual firms in our sample. In addition, we report the average realized volatility and bi-power variation for the S\&P 500, Dow Jones Industrial Average, and Russell 2000 equity indexes; and the 2-, 10-, and 30-year U.S. Treasury Securities.

The realized volatility (RV) approximates the total daily return variance, while the bi-power variation (BV) estimates the variance due to the continuous return component. We also report the square root of each of these variables, which can be interpreted as standard deviations. For individual stocks, we

\footnotetext{
${ }^{4}$ For example, on April 7, 2000, American Airlines had a TAQ record consisting of a bid quote of $\$ 68.125$ and an offer quote of $\$ 80$. All other bid-offer spreads for the day were much narrower, typically less than $\$ 0.25$, and thus our filter eliminated this bid and offer quote. We also found occurrences in the TAQ quote data where a quotation appeared to be a typographical error or seemed inconsistent with surrounding quotes. For example, a bid quote of $\$ 23.375$ for HCA on August 17, 2000, is followed by a bid quote of $\$ 33.375$, and surrounded by bid quotes of $\$ 33$ or greater throughout the trading day.

${ }^{5}$ For example, a sequence of three midpoint quotes for American Airlines on December 7, 2000, are as follows: $\$ 31.03$ for interval 1, $\$ 84.91$ for interval 2, and $\$ 30.66$ for interval 3. An examination of all other quotes for AA on December 7, 2000 suggested that the $\$ 84.91$ quote for interval 2 was invalid.

${ }^{6}$ At any point in time, each index or bond has numerous futures contracts with different maturities. We always use prices and returns from the outstanding futures contract with the shortest time to maturity.

${ }^{7}$ In much of the empirical previous work we examined, we found that most studies calculated the first interval return by using the closing midpoint quote from the previous trading day or just omitted the first interval from the daily jump calculation to prevent overnight factors from influencing the first interval return.

${ }^{8}$ For the component stocks of the S\&P 100 Index, we calculate returns for 78 five-minute intervals during the regular trading hours of 9:30 a.m.-4:00 p.m. EST. Dow 30 Index futures regularly trade between 8:20 a.m. and 4:15 p.m. EST, resulting in 96 five-minute intervals. Russell 2000 Index futures and S\&P 500 Index futures regularly trade between 9:30 a.m. and 4:15 p.m. EST, resulting in 82 five-minute intervals. Treasury futures trade regularly between 8:20 a.m. and 3:00 p.m. EST, resulting in 68 five-minute intervals.
} 
Table 1

\section{Summary Statistics of Return Data}

\begin{tabular}{|c|c|c|c|c|c|c|c|c|c|c|}
\hline & \multicolumn{4}{|c|}{$\begin{array}{l}\text { Cross-sectional Distribution for S\&P } \\
100 \text { Firms }\end{array}$} & \multicolumn{6}{|c|}{ Sample Means Reported } \\
\hline & Mean & Median & Min & Max & S\&P 500 & DJIA & $\begin{array}{l}\text { Russell } \\
2000\end{array}$ & $\begin{array}{l}\text { 2-Year } \\
\text { Bond }\end{array}$ & $\begin{array}{l}\text { 10-Year } \\
\text { Bond }\end{array}$ & $\begin{array}{l}\text { 30-Year } \\
\text { Bond }\end{array}$ \\
\hline \multicolumn{11}{|c|}{ Panel (a): Jump Model Parameters } \\
\hline $\begin{array}{l}\mathrm{RV} \\
\mathrm{RV}^{1 / 2} \\
\mathrm{BV}^{1 / 2} \\
\mathrm{BV}^{1 / 2} \\
\mathrm{BV} / \mathrm{RV} \\
(\mathrm{BV} / \mathrm{RV})^{1 / 2}\end{array}$ & $\begin{array}{l}0.0718 \% \\
2.6791 \% \\
0.0649 \% \\
2.5480 \% \\
0.9060 \\
0.9518\end{array}$ & $\begin{array}{l}0.0616 \% \\
2.4819 \% \\
0.0548 \% \\
2.3415 \% \\
0.9087 \\
0.9533\end{array}$ & $\begin{array}{l}0.0285 \% \\
1.6885 \% \\
0.0260 \% \\
1.6110 \% \\
0.8096 \\
0.8998\end{array}$ & $\begin{array}{l}0.2118 \% \\
4.6018 \% \\
0.1937 \% \\
4.4014 \% \\
0.9313 \\
0.9650\end{array}$ & $\begin{array}{l}0.0145 \% \\
1.2024 \% \\
0.0109 \% \\
1.0463 \% \\
0.8122 \\
0.9012\end{array}$ & $\begin{array}{l}0.0142 \% \\
1.1913 \% \\
0.0111 \% \\
1.0526 \% \\
0.8250 \\
0.9083\end{array}$ & $\begin{array}{l}0.0201 \% \\
1.4187 \% \\
0.0142 \% \\
1.1900 \% \\
0.7147 \\
0.8454\end{array}$ & $\begin{array}{l}0.0003 \% \\
0.1646 \% \\
0.0009 \% \\
0.0940 \% \\
0.4446 \\
0.6667\end{array}$ & $\begin{array}{l}0.0025 \% \\
0.5008 \% \\
0.0012 \% \\
0.3458 \% \\
0.7329 \\
0.8561\end{array}$ & $\begin{array}{l}0.0058 \% \\
0.7635 \% \\
0.0029 \% \\
0.5398 \% \\
0.7755 \\
0.8806\end{array}$ \\
\hline \multicolumn{11}{|c|}{ Panel (b): Risk Measures } \\
\hline $\begin{array}{l}\text { Total risk } \\
\text { Continuous risk } \\
\text { Jump risk } \\
\text { Corr(jump,cont) }\end{array}$ & $\begin{array}{l}4.4416 \% \\
4.0598 \% \\
0.3301 \% \\
0.0069\end{array}$ & $\begin{array}{l}3.6975 \% \\
3.4162 \% \\
0.2983 \% \\
0.0103\end{array}$ & $\begin{array}{l}1.6638 \% \\
1.5224 \% \\
0.1016 \% \\
-0.2036\end{array}$ & $\begin{array}{c}17.8787 \% \\
16.9654 \% \\
1.3234 \% \\
0.1398\end{array}$ & $\begin{array}{l}1.4348 \% \\
1.0074 \% \\
0.2793 \% \\
0.1397\end{array}$ & $\begin{array}{l}1.3504 \% \\
1.0185 \% \\
0.2346 \% \\
0.0995\end{array}$ & $\begin{array}{l}2.0840 \% \\
1.3746 \% \\
0.4694 \% \\
0.1494\end{array}$ & $\begin{array}{l}0.0227 \% \\
0.0074 \% \\
0.0164 \% \\
-0.0477\end{array}$ & $\begin{array}{l}0.2543 \% \\
0.1040 \% \\
0.1211 \% \\
0.1302\end{array}$ & $\begin{array}{l}0.6011 \% \\
0.2726 \% \\
0.2687 \% \\
0.1105\end{array}$ \\
\hline
\end{tabular}

Notes: Jump days are identified, and jump magnitudes calculated, according to the methodology described in the text, using 5-minute returns over the 1999-2005 sample period.

report the square root of each cross-sectional variance summary measure. Values for $\mathrm{RV}^{1 / 2}$ range from $0.16 \%$ for the two-year Treasury bond to $1.42 \%$ for the Russell 2000 Index. Not surprisingly, the volatility levels are significantly higher for individual stocks than for the equity indices.

The ratio of bi-power variation to realized volatility (BV/RV), or the square root of this ratio, has been used elsewhere in the literature to measure the fraction of total volatility generated by the continuous return component (Tauchen and Zhou 2006). From panel a one observes that, for the equity indexes, roughly $70-80 \%$ of unconditional return variance is due to the continuous component of returns. The percentage is similar for 10- and 30-year bonds, but for 2-year bonds only about $44 \%$ of total variance is attributable to the continuous return component. Interestingly, the continuous return component is largest among individual stocks, where approximately $90 \%$ of total return variance is attributable to continuous returns.

In panel b total returns are decomposed into their jump and continuous components, and the sample variances are calculated for each. Total risk is calculated as the variance of total daily returns. ${ }^{9}$ Continuous risk is calculated as the variance of daily continuous returns, where the daily continuous return is equal to the total daily return minus the daily jump return. Jump risk is the variance of daily jump returns, calculated using both jump and non-jump days. ${ }^{10}$ The percentage of total risk attributable to jumps is calculated as the jump variance divided by the total variance. The results of Panel $b$ in Table 1 indicate that, unconditionally, jumps contribute between $15 \%$ to $25 \%$ of the total variance for the equity indexes, $5 \%$ and $10 \%$ of total variance for individual stocks, and anywhere from $45 \%$ and $75 \%$ of the total variance for bonds.

Table 2, panel a, reports detailed statistics on the distribution of jumps across all firms and indexes in our sample. The jump frequency, defined as the number of days with a jump divided by the total number of days in the sample, varies considerably across firms, from a low of $7.7 \%$ for Exxon-Mobil to a high of $26.6 \%$ for Lucent Technologies and Comcast. In the stock futures market, jumps occur on $31 \%$ of trading days for the Dow, 33.5\% of trading days for the S\&P 500 Index, and 51\% of the trading

\footnotetext{
${ }^{9}$ Returns are obtained from the Center for Research in Security Prices (CRSP) daily U.S. stock return database.

${ }^{10}$ The value for the jump return is zero on nonjump days.
} 
Table 2

Distributional Properties of Jump Risk

\begin{tabular}{|c|c|c|c|c|c|c|c|c|c|c|}
\hline & \multicolumn{4}{|c|}{$\begin{array}{l}\text { Cross-sectional Distribution for Firms in } \\
\text { S\&P } 100\end{array}$} & \multicolumn{6}{|c|}{ Sample Means Reported } \\
\hline & Mean & Median & Min & Max & S\&P 500 & DJIA & $\begin{array}{c}\text { Russell } \\
2000\end{array}$ & $\begin{array}{l}\text { 2-Year } \\
\text { Bond }\end{array}$ & $\begin{array}{l}\text { 10-Year } \\
\text { Bond }\end{array}$ & $\begin{array}{l}\text { 30-Year } \\
\text { Bond }\end{array}$ \\
\hline \multicolumn{11}{|c|}{ Panel (a): All Jumps } \\
\hline $\begin{array}{l}\text { Jump frequency } \\
\text { Jump size } \\
\text { Absolute jump size } \\
\text { Absolute daily return } \\
\text { Jump variance } \\
\text { Total variance }\end{array}$ & $\begin{array}{c}12.069 \% \\
-0.0271 \\
1.3858 \\
1.5698 \\
2.7500 \\
4.6501\end{array}$ & $\begin{array}{c}11.421 \% \\
0.0030 \\
1.3579 \\
1.5169 \\
2.5208 \\
4.2258\end{array}$ & $\begin{array}{c}7.727 \% \\
-0.4045 \\
0.8939 \\
0.9676 \\
0.9705 \\
1.7224\end{array}$ & \begin{tabular}{|c}
$26.591 \%$ \\
0.4142 \\
2.2273 \\
2.5632 \\
8.3446 \\
11.4904
\end{tabular} & $\begin{array}{c}33.541 \% \\
0.0517 \\
0.7620 \\
1.0405 \\
0.8318 \\
1.9543\end{array}$ & \begin{tabular}{|c|}
$31.005 \%$ \\
0.0325 \\
0.7237 \\
0.9772 \\
0.7569 \\
1.6759
\end{tabular} & $\begin{array}{c}51.221 \% \\
0.0315 \\
0.8570 \\
1.1222 \\
0.9165 \\
2.1822\end{array}$ & $\begin{array}{c}70.417 \% \\
-0.0059 \\
0.0954 \\
0.0948 \\
0.0233 \\
0.0260\end{array}$ & $\begin{array}{c}46.316 \% \\
-0.0218 \\
0.2844 \\
0.3632 \\
0.2614 \\
0.3882\end{array}$ & $\begin{array}{c}38.207 \% \\
-0.0236 \\
0.4243 \\
0.5392 \\
0.7035 \\
1.0071\end{array}$ \\
\hline \multicolumn{11}{|c|}{ Panel (b): Jumps on Days of High Volatility } \\
\hline $\begin{array}{l}\text { Jump frequency } \\
\text { Jump size } \\
\text { Absolute jump size } \\
\text { Absolute daily return } \\
\text { Jump variance } \\
\text { Total variance }\end{array}$ & $\begin{array}{c}12.283 \% \\
-0.0411 \\
1.9114 \\
2.0887 \\
4.6658 \\
7.5115\end{array}$ & $\begin{array}{c}11.932 \% \\
-0.0370 \\
1.8811 \\
2.0175 \\
4.2791 \\
6.7129\end{array}$ & $\begin{array}{c}6.932 \% \\
-0.6229 \\
1.1627 \\
1.3047 \\
1.5026 \\
2.5658\end{array}$ & $\begin{array}{c}29.091 \% \\
0.5953 \\
3.0079 \\
3.6243 \\
16.1173 \\
25.3116\end{array}$ & $\begin{array}{c}39.253 \% \\
0.0508 \\
1.0076 \\
1.3808 \\
1.2917 \\
3.0045\end{array}$ & $\begin{array}{c}36.591 \% \\
0.0244 \\
0.9468 \\
1.2459 \\
1.1665 \\
2.4760\end{array}$ & $\begin{array}{c}51.818 \% \\
-0.0141 \\
1.0964 \\
1.4699 \\
1.4351 \\
3.4300\end{array}$ & $\begin{array}{c}69.143 \% \\
-0.0134 \\
0.1324 \\
0.1308 \\
0.0435 \\
0.0474\end{array}$ & $\begin{array}{c}49.029 \% \\
-0.0425 \\
0.3860 \\
0.4882 \\
0.4663 \\
0.6661\end{array}$ & $\begin{array}{c}41.143 \% \\
-0.0684 \\
0.5627 \\
0.7032 \\
1.2431 \\
1.7098\end{array}$ \\
\hline \multicolumn{11}{|c|}{ Panel (c): Jumps on Days When Market Jump Occurs } \\
\hline $\begin{array}{l}\text { Jump frequency } \\
\text { Jump size } \\
\text { Absolute jump size } \\
\text { Absolute daily return } \\
\text { Jump variance } \\
\text { Total variance }\end{array}$ & $\begin{array}{c}12.905 \% \\
0.0051 \\
1.3895 \\
1.5776 \\
2.6375 \\
4.5432\end{array}$ & $\begin{array}{c}12.137 \% \\
0.0063 \\
1.3618 \\
1.5441 \\
2.4826 \\
4.4153\end{array}$ & $\begin{array}{c}7.863 \% \\
-0.7183 \\
0.8419 \\
0.7449 \\
0.7870 \\
1.1687\end{array}$ & \begin{tabular}{|c}
$29.231 \%$ \\
0.5800 \\
2.4620 \\
2.8094 \\
7.4906 \\
14.8327
\end{tabular} & $\begin{array}{r}100.00 \% \\
0.0517 \\
0.7620 \\
1.0405 \\
0.8318 \\
1.9543\end{array}$ & $\begin{array}{c}59.658 \% \\
0.0755 \\
0.7983 \\
1.0521 \\
0.9318 \\
1.9714\end{array}$ & $\begin{array}{c}66.724 \% \\
0.1124 \\
0.9798 \\
1.2415 \\
1.2095 \\
2.5097\end{array}$ & $\begin{array}{c}74.055 \% \\
-0.0129 \\
0.1055 \\
0.1088 \\
0.0432 \\
0.0460\end{array}$ & $\begin{array}{c}49.828 \% \\
-0.0712 \\
0.3463 \\
0.4413 \\
0.5749 \\
0.7631\end{array}$ & $\begin{array}{c}41.753 \% \\
-0.0689 \\
0.5152 \\
0.6624 \\
1.6396 \\
2.1294\end{array}$ \\
\hline
\end{tabular}

Notes: Jump days are identified, and jump magnitudes calculated, according to the methodology described in the text, using 5-minute returns over the 1999-2005 sample period. Panel (a) includes all jumps. Panel (b) includes only jumps that occur on days of high realized volatility, defined to be days on which an asset's realized volatility is above that asset's median realized volatility calculated over the entire sample period.

days for the Russell 2000 Index. Approximately 40\% of trading days experience a jump in the 10- and 30 -year bond markets, and the 2-year Treasury experiences price jumps on $70 \%$ of trading days.

The average jump size is not significantly different from zero in either stock or bond futures markets. The absolute jump size provides a feel for the magnitude of jumps when they occur. Recall that on days when a jump occurs, the jump size is calculated as the square root of the difference between realized volatility and the bi-power variation measure. For stock indexes, the average absolute jump size ranges from 72 basis points for the Dow to 86 basis points for the Russell 2000. Average absolute bond jumps are smaller, ranging from 10 basis points for the 2-year bond to 42 basis points on the 30year bond. The average absolute jump size is highest among individual stocks, with a mean (median) absolute jump of $1.39 \%$ (1.36\%). Collectively, the summary statistics for individual stock jumps suggest that the jumps are relatively symmetrically distributed.

While Table 1 reported the relative contributions of jumps and continuous returns to unconditional risk, Table 2 breaks down total risk conditional upon a jump occurring. On days when jumps occur, jumps contribute about 59\% of total risk for individual stocks $(2.75 \% / 4.65 \%)$, and the jump contribution is above $50 \%$ for all individual stocks in the sample. For stock indexes, about $40-45 \%$ of total return variance is attributable to jumps on days when jumps occur, and the percentage is even higher for bonds. These results suggest that even when jump risk is relatively small on an unconditional basis, jumps can have a significant impact on volatility on days when they actually occur.

The methodology we use to identify statistically significant jumps does not require the jump to be economically large. Indeed, jumps as small as 10 basis points are not uncommon if the realized volatility is particularly low on a given day. This is because the methodology we use identifies jumps by "looking" for five-minute returns that are abnormally large when compared to the other five-minute returns on 
the same day. On days when the average five-minute return is very small, we may identify jumps that are statistically, but not economically, significant. ${ }^{11}$

To try to isolate economically meaningful jumps, panel b repeats the calculations in panel a using only those jumps that occur on high realized volatility days. We define a day to be a high-volatility day for a particular asset if the asset's realized volatility that day is above that asset's median realized volatility calculated over the entire sample period. Jumps occur slightly more frequently on highvolatility days, as can be seen by comparing the frequencies in panels a and b. The percentage of total risk attributable to jumps is slightly higher in panel $b$, but the percentages are fairly robust to whether or not we eliminate jumps on days of low volatility.

Because the market is simply the aggregation of individual stocks, it is interesting to ask what factors drive market jumps. To shed light on this question, panel e examines the distributional properties of jumps on days when the market experiences a jump, where the S\&P 500 futures contract is used as a market proxy. The results suggest that individual stocks are no more likely to experience jumps on days when the market jumps; and the average absolute jump size for individual stocks is roughly the same, regardless of whether or not the market experiences a jump (1.3895\% vs. $1.3858 \%$ in panel a). Thus, it appears that market jumps are not driven by either more or larger jumps among individual stocks.

What drives market jumps is an increased correlation in the jumps of individual stocks. On the 1,175 sample days when the market does not experience a jump, on average $49 \%$ of stocks experience a positive jump and $51 \%$ have a negative jump, and these averages are not statistically different from $50 \%$. Thus, the direction of individual firm jumps appears random on these days. However, on days when the market experiences a positive jump, 60.2\% of individual stocks also experience a positive jump; on days when the market has a negative jump, $62.2 \%$ of stocks have negative jumps. Both of these percentages are statistically different from 50\% at all standard significance levels. In addition, there is a strong positive correlation $(0.56, p$-value $<0.001)$ between average absolute market jump size and average absolute firm jump size, indicating that on days when the market experiences a particularly large jump, the average jump is larger for individual firms as well.

\subsection{Decomposing Systematic Risk into Continuous and Jump Components}

The distinction between systematic and nonsystematic risk has been explicitly recognized at least since Sharpe (1964), and jumps have been explicitly recognized in stochastic volatility and option pricing models for many years (Merton 1976; Bates 1991). To date, little work has examined the systematic and nonsystematic characteristics of jumps (for a recent theoretical exception, see Baek 2006). This section develops an empirical methodology that decomposes total jump risk into systematic and nonsystematic components.

It is common to express daily returns for an asset in terms of a factor model. Without loss of generality, consider the standard single-factor model (such as the CAPM) for the returns of asset $i$ :

$$
R_{i t}=\alpha_{i}+\beta_{i} R_{M}+\varepsilon_{i t} .
$$

Equation (4.1) does not distinguish between the continuous and jump components of total return, but does decompose total return into systematic $\left(\beta_{i} R_{M}\right)$ and nonsystematic $\left(\alpha_{i}+\varepsilon_{i t}\right)$ components. Any

\footnotetext{
${ }^{11}$ More specifically, the idea behind the estimation methodology is that the realized volatility (RV) includes volatility from both the continuous and jump processes and is estimated by summing squared returns. The bi-power variation (BV) measure captures only the continuous component and is estimated by summing the product of absolute return times lagged absolute return. The difference of the RV and BV terms reveals the relative contribution of jumps toward the day's total realized volatility. If prices move very little on a given day, it is frequently the case that there are multiple five-minute intervals with a return of $0 \%$. On such days the BV measure will be particularly small relative to RV (since BV involves products of lagged five-minute returns), and this can produce very large $z$-statistics even when an economically meaningful jump does not occur. Intuitively, the methodology identifies a day as having a significant jump when there are numerous runs of $0 \%$ returns, because any nonzero return is "large" relative to the surrounding $0 \%$ returns. Such days are eliminated by looking only at days with high absolute volatility.
} 
market jump is embedded in $R_{M}$, while any nonsystematic jump unique to firm $i$ is included in the error term. ${ }^{12}$

In this section we further decompose each stock's systematic risk into its continuous and jump components. ${ }^{13}$ This decomposition is interesting because standard factor models of risk implicitly assume that an asset's systematic risk is uncorrelated with jumps in the market (i.e., that the asset's beta does not change on days when the market experiences a jump). To our knowledge, the validity of this assumption has never been tested.

We first generalize equation (4.1) by decomposing each firm's total systematic risk into its continuous and jump components:

$$
R_{i t}=\alpha_{i}+\underbrace{\beta_{1 i}\left(R_{M t}-J_{M t}\right)}_{\begin{array}{c}
\text { continuous systematic } \\
\text { return }
\end{array}}+\underbrace{\beta_{2 i} J_{M t}}_{\begin{array}{c}
\text { jump systematic } \\
\text { return }
\end{array}}+\underbrace{\eta_{i t}}_{\begin{array}{c}
\text { nonsystematic } \\
\text { return }
\end{array}},
$$

where

$$
J_{M t}=\operatorname{sign}\left(R_{M t}\right) \times \sqrt{\left(R V_{t}-B V_{t}\right) \times I_{t}}
$$

and

$$
I_{t}=\left\{\begin{array}{ll}
1, & \text { if a jump occurs on day " } t \text { " } \\
0, & \text { otherwise }
\end{array}\right. \text {. }
$$

Here, $J_{M t}$ is the signed magnitude of the jump return for the market. The single-factor model is nested in equation (4.2) and corresponds to the special case of $\beta_{1 i}=\beta_{2 i}$. Table 3 reports cross-sectional summary statistics on the estimated parameters from both equations (4.1) and (4.2).

The top half of Table 3 compares each firm's total beta with its continuous and jump betas. The total beta is estimated by regressing total daily returns for each stock on the total daily return for the S\&P 500 market index and corresponds to a standard single-index model regression. The continuous and jump betas are estimated according to equation (4.2). For each firm we calculate the difference between the continuous and jump betas and report sample statistics on this difference.

The average total beta for the firms in our sample is about 0.68 , which suggests that these stocks have, on average, about $68 \%$ of the systematic risk possessed by the average stock. The average continuous beta is 0.80 , while the average jump beta is only 0.29 ; this difference between the average continuous and jump beta $(0.51)$ is statistically significant at the $1 \%$ level. The significantly lower jump

Table 3

\section{Decomposing Jump Risk into Systematic and Nonsystematic Components}

\begin{tabular}{|l|c|c|c|c|c|}
\hline & \multicolumn{4}{|c|}{ Cross-sectional Distribution for Firms in S\&P 100 } \\
\cline { 2 - 5 } & Mean & Median & Min & Max & Std Dev. \\
\hline Estimated parameter & & & & \\
Total return beta & 0.679 & 0.667 & 0.190 & 1.297 & 0.275 \\
Continuous beta & 0.803 & 0.769 & 0.295 & 1.544 & 0.314 \\
Jump beta & 0.287 & 0.310 & -0.191 & 0.828 & 0.218 \\
Difference (Cont - Jump) & $0.516^{* *}$ & $0.471^{* *}$ & 0.037 & 3.407 & $0.749 \%$ \\
Percentage total risk & $0.769 \%$ & $0.573 \%$ & $0.000 \%$ & 3.122 & 7.807 \\
Systematic jump risk & 15.202 & 14.013 & 3.593 & 24.009 & 3.496 \\
Systematic continuous risk & 8.665 & 8.436 & 2.348 & 90.646 & 8.430 \\
Nonsystematic jump risk & 75.364 & 76.883 & 53.023 & \\
Nonsystematic continuous risk & & & &
\end{tabular}

** Significant at the 0.01 level.

Notes: Jumps for individual equities are decomposed into their systematic and nonsystematic jump components.

\footnotetext{
${ }^{12}$ Although it would be interesting to explore jump and nonjump sensitivities to standard multifactor models, we are unable to obtain highfrequency data on these factors, which limits our analysis to a single-factor model.

${ }^{13}$ It is assumed that all jump risk for the diversified market indexes is systematic.
} 
beta relative to the continuous beta indicates that returns on individual stocks are most strongly correlated with market returns on days when the market does not experience a jump. ${ }^{14}$

\subsection{Decomposing Nonsystematic Risk into Continuous and Jump Components}

The error term in equation (4.2), $\eta_{i t}$, contains all nonsystematic risk (both continuous and jump). This section explicitly decomposes the total nonsystematic risk into its two components. Noting that the nonsystematic jump for firm $i$ is estimated by $\left(J_{i t}-\hat{\beta}_{2 i} J_{M t}\right)$, we define the nonsystematic continuous return component as the residual from equation (4.2) minus the nonsystematic jump:

$$
v_{i t}=\eta_{i t}-\left(J_{i t}-\hat{\beta}_{2 i} J_{M t}\right) \text {. }
$$

Thus, the methodology outlined above allows one to decompose the total return into its continuous and jump components, and in turn express each of these as the combination of a systematic and nonsystematic component.

We define total risk as the variance of total daily returns. The systematic risk can be decomposed into continuous and jump components as follows: systematic continuous (jump) risk is equal to the squared continuous (jump) beta times the variance of continuous (jump) market returns, or $\beta_{1 i}^{2} \sigma_{M k t, c o n t}^{2}$ and $\beta_{2 i}^{2} \sigma_{M k t, j u m p}^{2}$, respectively. Nonsystematic jump risk is defined as the sample variance of $\left[\left(J_{i t}-\hat{\beta}_{2 i} J_{M t}\right)\right]$, while continuous nonsystematic risk is estimated as the sample variance of $v_{i t}$ from equation (4.3).

The bottom half of Table 3 decomposes unconditional total risk into the four components just described. For the average stock in our sample, three-fourths of the total stock variance is continuous nonsystematic risk, while an additional $9 \%$ of total risk is nonsystematic jump risk. Thus, nearly $85 \%$ of total return variance is attributable to firm-specific factors. ${ }^{15}$ Interestingly, most jump risk is nonsystematic, with systematic jump risk contributing less than $1 \%$ of total return variance. This would suggest that accounting for jump risk is most important in a nondiversified context where nonsystematic risk is present.

\subsection{Regime-Dependent Correlations across Asset Markets}

Most investment and risk-management strategies depend on the correlations across different classes of assets. It is natural to ask whether such correlations are affected by the presence of a jump in financial markets. Table 4 reports cross-correlations between total daily returns for the three stock index and three bond futures contracts. Because the absolute jump size is considerably larger for stocks than for bonds (Table 2), we divide our sample based upon the presence or absence of jumps in the equity market. Panel a reports correlations on days when no jump occurs for the S\&P 500 futures contract, and Panel b reports correlations on days when the S\&P 500 futures contract experiences a jump. Panel c reports differences and indicates which correlations differ significantly between jump and nonjump days.

We find that stock-stock correlations are significantly higher on days when the equity market experiences a jump, while correlations between the 2-year Treasury bond and the 10- and 30-year Treasury bond are significantly lower. The 10-year-30-year Treasury bond correlation is also significantly higher.

\footnotetext{
${ }^{14}$ The average beta is low for several reasons. First, the sample contains the largest capitalization stocks in the market, and large-cap stock portfolios often have betas less than one. It is also low because we are using intraday returns. Including overnight returns for firms and the market yields an average beta of 0.87 . However, since the jump estimation methodology is not suited to incorporate overnight returns, we utilize intraday returns for both the individual stocks and the market proxy.

${ }^{15}$ These statistics decompose total variance, and not standard deviation, into its component parts because the variance components are additive while the standard deviation components are not. As a rough check, we note that our result that $85 \%$ of total risk is nonsystematic is roughly consistent with the well-documented empirical fact that the average U.S. stock has an annual return standard deviation of about $40 \%$ while the annual return standard deviation for the market is about $20 \%$. Using variances, this translates into approximately $20^{2} / 40^{2}=25 \%$ of total risk attributable to systematic factors.
} 
Table 4

Cross-correlations between Stocks and Bonds

\begin{tabular}{|c|c|c|c|c|c|c|}
\hline & DJIA & $\begin{array}{c}\text { Russell } \\
2000\end{array}$ & $\begin{array}{l}S \& P \\
500\end{array}$ & $\begin{array}{l}\text { 2-Year } \\
\text { Bond }\end{array}$ & $\begin{array}{l}\text { 10-Year } \\
\text { Bond }\end{array}$ & $\begin{array}{c}\text { 30-Year } \\
\text { Bond }\end{array}$ \\
\hline \multicolumn{7}{|c|}{ Panel (a) No-Jump Correlations } \\
\hline $\begin{array}{l}\text { DIIA } \\
\text { Russell } 2000 \\
\text { S\&P } 500 \\
\text { 2-year-bond } \\
\text { 10-year-bond } \\
\text { 30-year-bond }\end{array}$ & $\begin{array}{r}1.0000 \\
0.6508 \\
0.9216 \\
-0.1339 \\
-0.1400 \\
-0.1176\end{array}$ & $\begin{array}{r}1.0000 \\
0.7748 \\
-0.1597 \\
-0.1742 \\
-0.1477\end{array}$ & $\begin{array}{r}1.0000 \\
-0.1377 \\
-0.1405 \\
-0.1189\end{array}$ & $\begin{array}{l}1.0000 \\
0.8181 \\
0.7077\end{array}$ & $\begin{array}{l}1.0000 \\
0.9404\end{array}$ & 1.0000 \\
\hline \multicolumn{7}{|c|}{ Panel (b) Jump Regime Correlations } \\
\hline $\begin{array}{l}\text { DJIA } \\
\text { Russell } 2000 \\
\text { S\&P } 500 \\
\text { 2-year-bond } \\
\text { 10-year-bond } \\
\text { 30-year-bond }\end{array}$ & $\begin{array}{r}1.0000 \\
0.7959 \\
0.9538 \\
-0.1426 \\
-0.1693 \\
-0.1443\end{array}$ & $\begin{array}{r}1.0000 \\
0.8659 \\
-0.1367 \\
-0.1460 \\
-0.1089\end{array}$ & $\begin{array}{r}1.0000 \\
-0.1255 \\
-0.1511 \\
-0.1200\end{array}$ & $\begin{array}{l}1.0000 \\
0.3761 \\
0.3339\end{array}$ & $\begin{array}{l}1.0000 \\
0.9798\end{array}$ & 1.0000 \\
\hline \multicolumn{7}{|c|}{ Panel (c) Difference in Correlations betweeen Regimes (Jump-No Jump) } \\
\hline $\begin{array}{l}\text { Russell } 2000 \\
\text { S\&P } 500 \\
\text { 2-year-bond } \\
\text { 10-year-bond } \\
\text { 30-year-bond }\end{array}$ & $\begin{array}{l}0.1451^{* *} \\
0.0322^{* *} \\
-0.0087 \\
-0.0293 \\
-0.0267\end{array}$ & $\begin{array}{l}0.0911^{\star *} \\
0.0230 \\
0.0282 \\
0.0388\end{array}$ & $\begin{array}{r}0.0122 \\
-0.0106 \\
-0.0011\end{array}$ & $\begin{array}{l}-0.4420^{* *} \\
-0.3738^{* *}\end{array}$ & $0.0394^{\star *}$ & \\
\hline
\end{tabular}

Notes: Table reports correlations between three stock indices and the 2-year, 10-year and 30-year U.S. Treasury securities. Panel (a) includes only days on which no jump occurs for the S\&P 500 index, and panel (b) includes all days on which the S\&P 500 futures contract experiences a jump. Panel (c) indicates which correlations differ significantly between jump and no-jump days. ${ }^{* *}$ indicates statistically significant difference between jump and no-jump days at the 0.01 level.

Table 5

Cross-correlations between Continuous and Jump Return Components

\begin{tabular}{|c|c|c|c|c|c|c|}
\hline & DJIA & $\begin{array}{c}\text { Russell } \\
2000\end{array}$ & S\&P 500 & $\begin{array}{l}\text { 2-Year } \\
\text { Bond }\end{array}$ & $\begin{array}{l}\text { 10-year } \\
\text { Bond }\end{array}$ & $\begin{array}{c}\text { 30-Year } \\
\text { Bond }\end{array}$ \\
\hline \multicolumn{7}{|c|}{ Panel (a) Continuous Correlations } \\
\hline $\begin{array}{l}\text { DJIA } \\
\text { Russell } 2000 \\
\text { S\&P } 500 \\
2 \text {-year bond } \\
\text { 10-year bond } \\
\text { 30-year bond }\end{array}$ & $\begin{array}{r}1.0000 \\
0.6085 \\
0.8579 \\
-0.1555 \\
-0.1645 \\
-0.1247\end{array}$ & $\begin{array}{r}1.0000 \\
0.7031 \\
-0.1768 \\
-0.1791 \\
-0.1377\end{array}$ & $\begin{array}{r}1.0000 \\
-0.1384 \\
-0.1472 \\
-0.1099\end{array}$ & $\begin{array}{l}1.0000 \\
0.6348 \\
0.5523\end{array}$ & $\begin{array}{l}1.0000 \\
0.8643\end{array}$ & 1.0000 \\
\hline \multicolumn{7}{|c|}{ Panel (b) Jump Correlations } \\
\hline $\begin{array}{l}\text { DJIA } \\
\text { Russell } 2000 \\
\text { S\&P } 500 \\
\text { 2-year bond } \\
\text { 10-year bond } \\
\text { 30-year bond }\end{array}$ & $\begin{array}{r}1.0000 \\
0.4547 \\
0.6262 \\
-0.0540 \\
-0.0690 \\
-0.0439\end{array}$ & $\begin{array}{r}1.0000 \\
0.5071 \\
-0.0491 \\
-0.0225 \\
-0.1720\end{array}$ & $\begin{array}{r}1.0000 \\
-0.0596 \\
-0.0633 \\
-0.0343\end{array}$ & $\begin{array}{l}1.0000 \\
0.2525 \\
0.1607\end{array}$ & $\begin{array}{l}1.0000 \\
0.8841\end{array}$ & 1.0000 \\
\hline \multicolumn{7}{|c|}{ Panel (c) Difference in Correlations (Continuous-Jump) } \\
\hline $\begin{array}{l}\text { Russell } 2000 \\
\text { S\&P } 500 \\
2 \text {-year bond } \\
10 \text {-year bond } \\
30 \text {-year bond }\end{array}$ & $\begin{array}{l}0.1538^{* *} \\
0.2317^{* *} \\
0.1015^{* *} \\
0.0955^{* *} \\
0.0808^{* *}\end{array}$ & $\begin{array}{l}0.1960^{* *} \\
0.1277^{* *} \\
0.1566^{* *} \\
-0.0343\end{array}$ & $\begin{array}{l}0.0788^{* *} \\
0.0839^{* *} \\
0.0756^{* *}\end{array}$ & $\begin{array}{l}0.3823^{* *} \\
0.3916^{* *}\end{array}$ & $-0.0198^{\star *}$ & \\
\hline
\end{tabular}

Notes: Table reports correlations for returns between three stock indices and the 2-year, 10-year and 30-year U.S. Treasury securities. Panel (a) reports correlations of the continuous return component using all sample observations. Panel (b) reports correlations of the jump return component using all sample observations. Panel (c) reports the difference in the absolute continuous and jump correlations and indicates whether the difference is statistically different than zero. ${ }^{* *}$ indicates statistically significant difference between continuous and jump correlations at the 0.01 level. 
Moreover, the stock-bond correlations appear relatively stable in the presence of jumps, with none of the differences significant at either the $1 \%$ or 5\% levels. Thus, while intra-asset correlations seem dependent on the presence of a jump, inter-asset correlations do not.

Table 5 breaks down the total daily return into continuous and jump components and examines separately the cross-asset correlation for each. Panel a reports correlations for the continuous portion of returns, and panel b reports jump correlations. Panel c reports the absolute difference between continuous and jump correlations and indicates whether the difference is statistically different than zero. Jump correlations are almost uniformly weaker, as indicated by the positive absolute differences in panel c, and the differences between continuous and jump correlations are statistically significant for all but the Russell 2000-30-year Treasury bond correlation. In addition, many of the jump correlations between stock index and Treasury bond futures in panel b are themselves not significantly different from zero (significance levels omitted for brevity, but available upon request). Taken together, the results of Table 5 tell us that the majority of asset correlation is driven by the underlying continuous return components, and that jumps appear relatively uncorrelated, particularly when looking across different asset classes.

\subsection{Robustness Checks}

We examine the robustness of our results across several dimensions. First, we have repeated our analysis excluding returns in the first and last 15 minutes of the trading day; the jump distribution statistics are reported in Appendix Table 6. The average jump frequency for individual stocks is $6.07 \%$, versus $12.069 \%$ when the first and last 15 minutes are included (Table 2). Thus, it appears that approximately half of the daily jumps are concentrated in the first or last 15 minutes of trading. The average absolute jump size and daily return are slightly smaller when these returns are omitted, but the distributional properties are generally similar to the more general results reported in Table 2, which suggests that although a large percentage of jumps occur in the first and last 15 minutes of trading, these jumps are not materially different from the other jumps occurring throughout the day. Second, to examine the sensitivity of our results to our choice of the significance level, we repeat the analysis in Table 2 for $Z J_{t}=2.0$ and $Z J_{t}=4.0$. The results are reported in Appendix Tables 7 and 8 . Relative to the choice of $Z J_{t}=3.0$, the jump frequency is slightly higher when $Z J_{t}=2.0(13.892 \%)$, and much lower when $Z J_{t}=4.0(2.888 \%)$. Absolute jump sizes are lower under $Z J_{t}=2.0$ and slightly higher under $Z J_{t}=4.0$.

Appendix Table 9 reports the variance decomposition for each of the three robustness specifications. Although the actual numbers differ in each specification, the qualitative results are similar: approximately $75-80 \%$ of total variance is attributable to nonsystematic continuous risk, and $15-20 \%$ of the remaining variance comes from systematic continuous risk. Nonsystematic jump risk contributes between $3 \%$ and $8 \%$ of total variance, and systematic jump risk is less than $1 \%$ of total variance in all cases.

\section{Conclusion}

This study utilizes recently developed econometric techniques to separate the jump return component from the underlying continuous diffusion process. We estimate and examine the distributional properties of jump risk across a large number of assets. Our results suggest that jumps contribute between $15 \%$ and $25 \%$ of the total unconditional intraday return variance for equity indexes, and between $45 \%$ and $75 \%$ of the total unconditional intraday return variance for Treasury securities. Conditional on a jump occurring, jumps contribute at least $50 \%$ of total intraday return volatility for individual stocks; slightly less for stock indexes; and slightly more for bond indexes. In addition, jumps contribute between $80 \%$ and $90 \%$ of the total absolute intraday return on days when jumps occur.

When applied to the component stocks of the S\&P 100 Index, our jump detection methodology indicates that the mean continuous beta and the mean jump beta differ significantly in the cross section. Specifically, the average continuous beta (0.80) is nearly three times the average jump beta 
(0.29), which indicates that intraday returns on individual stocks are most strongly correlated with market returns on days when the market does not experience a jump.

For the average stock in our sample, three-fourths of the total stock variance is continuous nonsystematic risk, while an additional $9 \%$ of total risk is nonsystematic jump risk. Thus, nearly $85 \%$ of total return variance is attributable to firm-specific factors. Most jump risk is nonsystematic, with systematic jump risk contributing less than $1 \%$ of total return variance.

We find that stock-stock correlations are significantly higher on days when the equity market experiences a jump. In contrast, the stock-bond correlations appear relatively stable in the presence of jumps. Thus, while intra-asset correlations seem dependent on the presence of a jump, inter-asset correlations do not. In addition, we find that the majority of asset correlation is driven by the underlying continuous return component, and that jumps appear relatively uncorrelated, particularly when looking across different asset classes. On days of high realized volatility, jumps contribute between $70 \%$ and $80 \%$ of the total absolute daily return.

Oftentimes actuaries are concerned about the stochastic behavior of long-horizon market returns as they relate to the long-horizon nature of insurance liabilities. While our analysis of the distributional properties of high-frequency returns does not lend itself to long-horizon actuarial applications, our findings do have at least two important implications for risk management. First, most jump risk is nonsystematic, which suggests that accounting for jump risk is most critical in a nondiversified context (such as hedging individual securities) where nonsystematic risk is present. Thus, for actuaries managing diversified portfolios, our results suggest that the majority of jump risk in individual securities is diversified away. At the same time, some of the jump risk does aggregate, and therefore our results related to jump distributions at the market level are more broadly relevant for actuaries managing investment portfolios.

We also find that jump betas are substantially lower than continuous betas. This finding has implications for actuarial risk management practices such as the calculation of Value at Risk (VaR), which estimates the probability of a portfolio return falling below a critical threshold. VaR may be calculated over various time horizons, and the most direct application of our results is to short-horizon VaR calculations. Such calculations are most important for days on which the market experiences a downward jump, and yet our results indicate that it is precisely on such jump days that individual asset betas are lower. Failure to account for this property of stock returns may cause actuaries to overestimate the risk of the underlying portfolio, and therefore overestimate their portfolio's Value at Risk. This could explain the results of Perignon, Deng, and Wang (2006), who find evidence of substantial conservatism bias in the VaR estimates of the six largest Canadian commercial banks.

\section{APPENDIX}

Table 6

Distributional Properties of Jump Risk (Exclude First and Last 15 Minutes, $Z=3$ )

\begin{tabular}{|c|c|c|c|c|c|c|c|c|c|c|}
\hline & \multicolumn{4}{|c|}{$\begin{array}{l}\text { Cross-sectional Distribution for Firms in } \\
\qquad \text { S\&P } 100\end{array}$} & \multicolumn{6}{|c|}{ Sample Means Reported } \\
\hline & Mean & Median & Min & Max & S\&P 500 & DJIA & $\begin{array}{l}\text { Russell } \\
2000\end{array}$ & $\begin{array}{l}\text { 2-Year } \\
\text { Bond }\end{array}$ & $\begin{array}{l}\text { 10-Year } \\
\text { Bond }\end{array}$ & $\begin{array}{c}\text { 30-Year } \\
\text { Bond }\end{array}$ \\
\hline \multicolumn{11}{|c|}{ Panel (a): All Jumps } \\
\hline Jump frequency & $6.070 \%$ & $5.625 \%$ & $0.000 \%$ & $17.841 \%$ & $6.109 \%$ & $9.256 \%$ & $33.049 \%$ & $53.341 \%$ & $10.280 \%$ & $7.767 \%$ \\
\hline Jump size & -0.0558 & -0.0459 & -0.5272 & 0.2871 & -0.0010 & -0.0083 & -0.0092 & 0.0039 & 0.0041 & -0.0219 \\
\hline Absolute jump size & 1.2772 & 1.2300 & 0.7932 & 2.0812 & 0.5192 & 0.4879 & 0.8258 & 0.0608 & 0.1701 & 0.2566 \\
\hline Absolute daily return & 1.3815 & 1.3666 & 0.6241 & 2.3741 & 0.8470 & 0.7137 & 0.6262 & 0.0611 & 0.2446 & 0.3498 \\
\hline Jump variance & 2.4689 & 2.2300 & 0.7598 & 15.6740 & 0.0243 & 0.0303 & 0.1420 & 0.0024 & 0.0038 & 0.0061 \\
\hline Total variance & 3.8737 & 3.4756 & 0.75516 & 21.6810 & 1.0164 & 0.9083 & 1.4862 & 0.8169 & 0.1025 & 0.2521 \\
\hline
\end{tabular}


Table 6

\section{(continued)}

\begin{tabular}{|c|c|c|c|c|c|c|c|c|c|c|}
\hline & \multicolumn{4}{|c|}{$\begin{array}{l}\text { Cross-sectional Distribution for Firms in } \\
\text { S\&P } 100\end{array}$} & \multicolumn{6}{|c|}{ Sample Means Reported } \\
\hline & Mean & Median & Min & Max & S\&P 500 & DJIA & $\begin{array}{c}\text { Russell } \\
2000\end{array}$ & $\begin{array}{l}\text { 2-Year } \\
\text { Bond }\end{array}$ & $\begin{array}{l}\text { 10-Year } \\
\text { Bond }\end{array}$ & $\begin{array}{l}\text { 30-Year } \\
\text { Bond }\end{array}$ \\
\hline \multicolumn{11}{|c|}{ Panel (b): Jumps on Days of High Volatility } \\
\hline $\begin{array}{l}\text { Jump frequency } \\
\text { Jump size } \\
\text { Absolute jump size } \\
\text { Absolute daily return } \\
\text { Jump variance } \\
\text { Total variance }\end{array}$ & $\begin{array}{c}6.538 \% \\
-0.0407 \\
1.7277 \\
1.7877 \\
4.0416 \\
5.9894\end{array}$ & \begin{tabular}{|c|}
$5.852 \%$ \\
-0.0423 \\
1.6650 \\
1.7256 \\
3.4210 \\
5.3194
\end{tabular} & $\begin{array}{c}1.818 \% \\
-0.8138 \\
1.0178 \\
0.7463 \\
1.1593 \\
1.0676\end{array}$ & $\begin{array}{c}15.682 \% \\
0.5368 \\
2.9395 \\
3.3613 \\
25.8736 \\
39.7823\end{array}$ & $\begin{array}{l}6.448 \% \\
0.0217 \\
0.7019 \\
1.1391 \\
0.0427 \\
1.6082\end{array}$ & \begin{tabular}{|c|}
$7.841 \%$ \\
-0.0380 \\
0.6872 \\
0.9174 \\
0.0483 \\
1.4407
\end{tabular} & $\begin{array}{c}26.818 \% \\
-0.0943 \\
0.7825 \\
1.0760 \\
0.1739 \\
2.1912\end{array}$ & $\begin{array}{c}46.057 \% \\
0.0050 \\
0.0800 \\
0.0808 \\
0.0034 \\
0.0132\end{array}$ & $\begin{array}{c}8.343 \% \\
-0.0085 \\
0.2386 \\
0.3360 \\
0.0056 \\
0.1604\end{array}$ & $\begin{array}{r}6.514 \% \\
-0.0602 \\
0.3430 \\
0.4620 \\
0.0086 \\
0.3837\end{array}$ \\
\hline \multicolumn{11}{|c|}{ Panel (c): Jumps on Days When Market Jump Occurs } \\
\hline $\begin{array}{l}\text { Jump frequency } \\
\text { Jump size } \\
\text { Absolute jump size } \\
\text { Absolute daily return } \\
\text { Jump variance } \\
\text { Total variance }\end{array}$ & \begin{tabular}{|c|}
$7.632 \%$ \\
-0.0032 \\
1.3264 \\
1.4219 \\
2.2481 \\
3.4929
\end{tabular} & $\begin{array}{c}7.477 \% \\
-0.0051 \\
1.2581 \\
1.2788 \\
1.7628 \\
2.5443\end{array}$ & $\begin{array}{c}0.000 \% \\
-2.1739 \\
0.6624 \\
0.2477 \\
0.0676 \\
0.0957\end{array}$ & $\begin{array}{c}21.495 \% \\
2.1108 \\
3.4813 \\
4.4450 \\
24.6504 \\
54.7856\end{array}$ & $\begin{array}{r}100.00 \% \\
-0.0105 \\
0.5192 \\
0.8470 \\
0.4020 \\
1.3670\end{array}$ & $\begin{array}{c}39.252 \% \\
-0.0001 \\
0.6023 \\
0.8117 \\
0.5418 \\
1.2233\end{array}$ & $\begin{array}{c}30.556 \% \\
0.0781 \\
0.7149 \\
0.9525 \\
0.6525 \\
1.7670\end{array}$ & $\begin{array}{c}60.377 \% \\
-0.0013 \\
0.0637 \\
0.0654 \\
0.0059 \\
0.0080\end{array}$ & $\begin{array}{c}12.264 \% \\
0.0768 \\
0.2218 \\
0.3195 \\
0.0780 \\
0.1554\end{array}$ & \begin{tabular}{|c|}
$5.660 \%$ \\
-0.0051 \\
0.4415 \\
0.8347 \\
0.3028 \\
1.2432
\end{tabular} \\
\hline
\end{tabular}

Notes: Jump days are identified, and jump magnitudes calculated, according to the methodology described in the text, using 5-minute return over the 1999-2005 sample period. Panel (a) includes all jumps. Panel (b) includes only jumps that occur on days of high realized volatility, defined to be days on which an asset's realized volatility is above that asset's median realized volatility calculated over the entire sample period.

Table 7

Distributional Properties of Jump Risk (Open to Close, $Z=2$ )

\begin{tabular}{|c|c|c|c|c|c|c|c|c|c|c|}
\hline & \multicolumn{4}{|c|}{$\begin{array}{l}\text { Cross-sectional Distribution for Firms in } \\
\text { S\&P } 100\end{array}$} & \multicolumn{6}{|c|}{ Sample Means Reported } \\
\hline & Mean & Median & Min & Max & S\&P 500 & DJIA & $\begin{array}{c}\text { Russell } \\
2000\end{array}$ & $\begin{array}{l}\text { 2-Year } \\
\text { Bond }\end{array}$ & $\begin{array}{l}\text { 10-Year } \\
\text { Bond }\end{array}$ & $\begin{array}{l}\text { 30-Year } \\
\text { Bond }\end{array}$ \\
\hline \multicolumn{11}{|c|}{ Panel (a): All Jumps } \\
\hline $\begin{array}{l}\text { Jump frequency } \\
\text { Jump size } \\
\text { Absolute jump size } \\
\text { Absolute daily return } \\
\text { Jump variance } \\
\text { Total variance }\end{array}$ & $\begin{array}{c}13.892 \% \\
-0.0409 \\
1.0953 \\
1.3622 \\
1.7688 \\
3.7483\end{array}$ & $\begin{array}{c}13.125 \% \\
-0.0503 \\
1.0538 \\
1.3230 \\
1.5882 \\
3.4228\end{array}$ & $\begin{array}{c}7.330 \% \\
-0.2335 \\
0.7261 \\
0.6832 \\
0.6318 \\
0.8912\end{array}$ & \begin{tabular}{|c}
$29.659 \%$ \\
0.1994 \\
1.7915 \\
2.4286 \\
6.3210 \\
14.3453
\end{tabular} & $\begin{array}{c}47.059 \% \\
0.0337 \\
0.6723 \\
0.9622 \\
0.6708 \\
1.6928\end{array}$ & $\begin{array}{c}48.552 \% \\
0.0167 \\
0.6181 \\
0.9171 \\
0.5645 \\
1.5128\end{array}$ & $\begin{array}{c}67.291 \% \\
0.0310 \\
0.7979 \\
1.1023 \\
0.7966 \\
2.0595\end{array}$ & $\begin{array}{c}79.383 \% \\
-0.0044 \\
0.0930 \\
0.0964 \\
0.0214 \\
0.0252\end{array}$ & $\begin{array}{c}60.937 \% \\
-0.0129 \\
0.2558 \\
0.3439 \\
0.2066 \\
0.3262\end{array}$ & $\begin{array}{c}54.597 \% \\
-0.0193 \\
0.3739 \\
0.5137 \\
0.5142 \\
0.8046\end{array}$ \\
\hline \multicolumn{11}{|c|}{ Panel (b): Jumps on Days of High Volatility } \\
\hline $\begin{array}{l}\text { Jump frequency } \\
\text { Jump Size } \\
\text { Absolute jump size } \\
\text { Absolute daily return } \\
\text { Jump variance } \\
\text { Total variance }\end{array}$ & $\begin{array}{c}14.416 \% \\
-0.0406 \\
1.4985 \\
1.7838 \\
2.9705 \\
5.9499\end{array}$ & $\begin{array}{c}13.864 \% \\
-0.0039 \\
1.4457 \\
1.7104 \\
2.6612 \\
4.9698\end{array}$ & $\begin{array}{c}7.273 \% \\
-0.4274 \\
0.9321 \\
0.8410 \\
0.9601 \\
1.2378\end{array}$ & $\begin{array}{c}30.795 \% \\
0.4432 \\
2.4643 \\
3.3585 \\
13.3538 \\
30.2727\end{array}$ & $\begin{array}{c}51.584 \% \\
0.0245 \\
0.9173 \\
1.3024 \\
1.0979 \\
2.7041\end{array}$ & $\begin{array}{c}51.477 \% \\
0.0050 \\
0.8464 \\
1.2115 \\
0.9427 \\
2.3808\end{array}$ & $\begin{array}{c}65.568 \% \\
-0.0161 \\
1.0304 \\
1.4417 \\
1.2709 \\
3.2510\end{array}$ & $\begin{array}{c}80.914 \% \\
-0.0112 \\
0.1261 \\
0.1305 \\
0.0385 \\
0.0441\end{array}$ & $\begin{array}{c}61.714 \% \\
-0.0297 \\
0.3523 \\
0.4642 \\
0.3821 \\
0.5714\end{array}$ & $\begin{array}{c}56.000 \% \\
-0.0578 \\
0.4993 \\
0.6782 \\
0.9425 \\
1.4002\end{array}$ \\
\hline \multicolumn{11}{|c|}{ Panel (c): Jumps on Days When Market Jump Occurs } \\
\hline $\begin{array}{l}\text { Jump frequency } \\
\text { Jump size } \\
\text { Absolute jump size } \\
\text { Absolute daily return } \\
\text { Jump variance } \\
\text { Total variance }\end{array}$ & $\begin{array}{c}14.318 \% \\
-0.0111 \\
1.0844 \\
1.3558 \\
1.7643 \\
3.7363\end{array}$ & $\begin{array}{c}13.228 \% \\
-0.0106 \\
1.0401 \\
1.3142 \\
1.5417 \\
3.2565\end{array}$ & $\begin{array}{c}7.160 \% \\
-0.4411 \\
0.7200 \\
0.6291 \\
0.6390 \\
0.7580\end{array}$ & $\begin{array}{r}31.43 \% \\
0.3600 \\
1.7326 \\
2.5433 \\
12.3277 \\
12.9093\end{array}$ & $\begin{array}{r}100.00 \% \\
0.0337 \\
0.6723 \\
0.9622 \\
0.6708 \\
1.6928\end{array}$ & $\begin{array}{c}69.417 \% \\
0.0231 \\
0.6793 \\
0.9692 \\
0.6910 \\
1.6760\end{array}$ & $\begin{array}{c}76.485 \% \\
0.0988 \\
0.8817 \\
1.1741 \\
0.9934 \\
2.2751\end{array}$ & $\begin{array}{c}80.318 \% \\
-0.0091 \\
0.1010 \\
0.1071 \\
0.0342 \\
0.0377\end{array}$ & $\begin{array}{c}63.692 \% \\
-0.0317 \\
0.2865 \\
0.3790 \\
0.3485 \\
0.4940\end{array}$ & $\begin{array}{c}58.313 \% \\
-0.0307 \\
0.4108 \\
0.5579 \\
0.8903 \\
1.2428\end{array}$ \\
\hline
\end{tabular}

Notes: Jump days are identified, and jump magnitudes calculated, according to the methodology described in the text, using 5-minute returns over the 1999-2005 sample period. Panel (a) includes all jumps. Panel (b) includes only jumps that occur on days of high realized volatility, defined to be days on which an asset's realized volatility is above that asset's median realized volatility calculated over the entire sample period. 
Table 8

Distributional Properties of Jump Risk (Open to Close, $Z=4$ )

\begin{tabular}{|c|c|c|c|c|c|c|c|c|c|c|}
\hline & \multicolumn{4}{|c|}{$\begin{array}{l}\text { Cross-sectional Distribution for Firms in } \\
\text { S\&P } 100\end{array}$} & \multicolumn{6}{|c|}{ Sample Means Reported } \\
\hline & Mean & Median & Min & Max & S\&P 500 & DJIA & $\begin{array}{l}\text { Russell } \\
2000\end{array}$ & $\begin{array}{l}\text { 2-Year } \\
\text { Bond }\end{array}$ & $\begin{array}{l}\text { 10-Year } \\
\text { Bond }\end{array}$ & $\begin{array}{l}\text { 30-Year } \\
\text { Bond }\end{array}$ \\
\hline \multicolumn{11}{|c|}{ Panel (a): All Jumps } \\
\hline $\begin{array}{l}\text { Jump frequency } \\
\text { Jump size } \\
\text { Absolute jump size } \\
\text { Absolute daily return } \\
\text { Jump variance } \\
\text { Total variance }\end{array}$ & $\begin{array}{c}2.888 \% \\
-0.0696 \\
1.4689 \\
1.3743 \\
3.2839 \\
3.8687 \\
\end{array}$ & $\begin{array}{c}2.614 \% \\
-0.0730 \\
1.4046 \\
1.3471 \\
2.8530 \\
3.7016\end{array}$ & $\begin{array}{c}0.852 \% \\
-0.9701 \\
0.8431 \\
0.6344 \\
0.8065 \\
0.7825 \\
\end{array}$ & \begin{tabular}{|c|}
$11.364 \%$ \\
0.6496 \\
2.4320 \\
2.4361 \\
37.9314 \\
38.2807 \\
\end{tabular} & $\begin{array}{c}22.964 \% \\
0.1012 \\
0.8658 \\
1.1479 \\
1.0454 \\
2.2426 \\
\end{array}$ & $\begin{array}{c}20.500 \% \\
0.0115 \\
0.8307 \\
1.0591 \\
0.9777 \\
1.9577\end{array}$ & $\begin{array}{c}35.378 \% \\
0.0698 \\
0.9146 \\
1.1086 \\
1.0101 \\
2.1113\end{array}$ & $\begin{array}{c}61.508 \% \\
-0.0066 \\
0.0973 \\
0.0938 \\
0.0254 \\
0.0273\end{array}$ & $\begin{array}{c}34.495 \% \\
-0.0383 \\
0.3147 \\
0.3819 \\
0.3342 \\
0.4583\end{array}$ & $\begin{array}{c}27.756 \% \\
-0.0482 \\
0.4711 \\
0.5818 \\
0.9267 \\
1.2641\end{array}$ \\
\hline \multicolumn{11}{|c|}{ Panel (b): Jumps on Days of High Volatility } \\
\hline $\begin{array}{l}\text { Jump frequency } \\
\text { Jump size } \\
\text { Absolute jump size } \\
\text { Absolute daily return } \\
\text { Jump variance } \\
\text { Total variance }\end{array}$ & $\begin{array}{c}3.174 \% \\
-0.0508 \\
1.9524 \\
1.7810 \\
5.1929 \\
5.8910\end{array}$ & $\begin{array}{c}2.841 \% \\
-0.0551 \\
1.8839 \\
1.6743 \\
4.1676 \\
4.9880\end{array}$ & \begin{tabular}{|c|}
$0.682 \%$ \\
-1.5454 \\
1.0269 \\
0.7868 \\
1.1310 \\
1.1450
\end{tabular} & \begin{tabular}{|}
$7.386 \%$ \\
1.1117 \\
3.2192 \\
3.8171 \\
62.0134 \\
61.7142
\end{tabular} & $\begin{array}{c}29.299 \% \\
0.1230 \\
1.0986 \\
1.4495 \\
1.5147 \\
3.2131\end{array}$ & $\begin{array}{c}26.705 \% \\
-0.0082 \\
1.0404 \\
1.3030 \\
1.3954 \\
2.7100\end{array}$ & $\begin{array}{c}36.136 \% \\
0.0442 \\
1.1707 \\
1.4339 \\
1.5728 \\
3.3082\end{array}$ & $\begin{array}{c}58.629 \% \\
-0.0149 \\
0.1378 \\
0.1322 \\
0.0490 \\
0.0515\end{array}$ & $\begin{array}{c}37.943 \% \\
-0.0631 \\
0.4236 \\
0.5043 \\
0.5790 \\
0.7671\end{array}$ & $\begin{array}{c}31.771 \% \\
-0.1074 \\
0.6121 \\
0.7498 \\
1.5530 \\
2.0629\end{array}$ \\
\hline \multicolumn{11}{|c|}{ Panel (c): Jumps on Days When Market Jump Occurs } \\
\hline $\begin{array}{l}\text { Jump frequency } \\
\text { Jump size } \\
\text { Absolute jump size } \\
\text { Absolute daily return } \\
\text { Jump variance } \\
\text { Total variance }\end{array}$ & \begin{tabular}{l|}
$3.045 \%$ \\
0.0186 \\
1.4988 \\
1.5020 \\
3.0078 \\
3.9199
\end{tabular} & $\begin{array}{l}2.513 \% \\
0.0595 \\
1.4018 \\
1.3796 \\
2.4463 \\
3.0876\end{array}$ & $\begin{array}{c}0.752 \% \\
-0.0210 \\
0.7400 \\
0.3412 \\
0.3301 \\
0.1413\end{array}$ & \begin{tabular}{|c|}
$10.526 \%$ \\
2.6258 \\
3.0305 \\
3.6671 \\
15.7715 \\
44.6831 \\
\end{tabular} & \begin{tabular}{|r|}
$100.00 \%$ \\
0.1012 \\
0.8658 \\
1.1479 \\
1.0453 \\
2.2426
\end{tabular} & \begin{tabular}{c|}
$55.138 \%$ \\
0.0875 \\
0.9376 \\
1.2045 \\
1.2451 \\
2.4871
\end{tabular} & $\begin{array}{c}58.500 \% \\
0.2727 \\
1.0683 \\
1.2871 \\
1.2859 \\
2.5106\end{array}$ & $\begin{array}{c}65.404 \% \\
-0.0156 \\
0.1109 \\
0.1072 \\
0.0596 \\
0.0600\end{array}$ & $\begin{array}{c}40.404 \% \\
-0.0359 \\
0.3339 \\
0.3964 \\
0.1460 \\
0.2646\end{array}$ & $\begin{array}{c}32.828 \% \\
0.0068 \\
0.4792 \\
0.6085 \\
0.2764 \\
0.5999\end{array}$ \\
\hline
\end{tabular}

Notes: Jump days are identified, and jump magnitudes calculated, according to the methodology described in the text, using 5-minute returns over the 1999-2005 sample period. Panel (a) includes all jumps. Panel (b) includes only jumps that occur on days of high realized volatility, defined to be days on which an asset's realized volatility is above that asset's median realized volatility calculated over the entire sample period.

Table 9

\section{Decomposing Jump Risk into Systematic and Nonsystematic Components}

\begin{tabular}{|l|c|c|c|}
\hline & \multicolumn{3}{|c|}{ Excluding First and Last 15 Minutes } \\
\cline { 2 - 4 } Percentage Total Risk & $Z=3.0$ & $Z=4.0$ & $Z=\mathbf{2 . 0}$ \\
\hline Systematic jump risk & $0.704 \%$ & $0.438 \%$ & $0.826 \%$ \\
Systematic continuous risk & 20.322 & 15.909 & 14.812 \\
Nonsystematic jump risk & 4.959 & 3.329 & 7.812 \\
Nonsystematic continuous risk & 74.014 & 80.323 & 76.549 \\
\hline
\end{tabular}

Note: Jumps for individual equities are decomposed into their systematic and nonsystematic jump components.

\section{REFERENCES}

Aït-Sahalia, Y. 2004. Disentangling Diffusion from Jumps. Journal of Financial Economics 74: 487-528.

Anderson, T., And T. Bollerslev. 1998. Answering the Skeptics: Yes, Standard Volatility Models Do Provide Accurate Forecasts. International Economic Review 39: 885-905.

Anderson, T., T. Bollerslev, and F. Diebold. 2007. Roughing It Up: Disentangling Continuous and Jump Components in Measuring, Modeling and Forecasting Asset Return Volatility. Journal of Economics and Statistics, forthcoming.

BAEK, C. 2006. A Comparison of Alternative Option Pricing Models: Systematic vs. Mixed Systematic/Diversifiable Jump Diffusion. Ph.D. dissertation, University of Nebraska-Lincoln.

Barndorff-Nielsen, O., and N. Shephard. 2004. Power and Bi-power Variation with Stochastic Volatility and Jumps. Journal of Financial Econometrics 2: 1-48.

BAtes, O. 1991. Jumps and Stochastic Volatility: Exchange Rate Processes Implicit in Deutsche Mark Options. Review of Financial Econometrics 9: 69-107.

CaO, C. Q., ANd R. S. Tsay. 1992. Nonlinear Time-Series Analysis of Stock Volatilities. Journal of Applied Econometrics 7: S165-85. Hansen, P., And A. Lunde. 2005. Realized Variance and Market Microstructure Noise. Journal of Business \& Economic Statistics 24: 195-202. 
Hardy, M. R. 2001. A Regíme-Switching Model of Long-Term Stock Returns. North American Actuarial Journal 5(2): 41-53. Martens, M. 2002. Measuring and Forecasting S\&P 500 Index-Futures Volatility Using High-Frequency Data. Journal of Futures Markets 22: 497-518.

Merton, R. 1976. Option Pricing When Underlying Stock Returns Are Discontinuous. Journal of Financial Economics 63: 3-50. Perignon, C., Z. Deng, And Z. Wang. 2006. Do Banks Overstate Their Value-at-Risk? Working Paper, Simon Fraser University. Sharpe, W. 1964. Capital Asset Prices: A Theory of Market Equilibrium under Conditions of Risk. Journal of Finance 19: 425-42. Tauchen, G., And H. Zhou. 2006. Realized Jumps on Financial Markets and Predicting Credit Spreads. Finance and Economics Discussion Series 2006-35, Board of Governors of the Federal Reserve System.

Discussions on this paper can be submitted until April 1, 2008. The authors reserve the right to reply to any discussion. Please see the Submission Guidelines for Authors on the inside back cover for instructions on the submission of discussions. 